\title{
THE IMPACT OF AGE, CORONARY ARTERY DISEASE, AND CARDIAC COMORBIDITY ON LATE SURVIVAL AFTER BIOPROSTHETIC AORTIC VALVE REPLACEMENT
}

Gideon Cohen, MD

Tirone E. David, MD

Joan Ivanov, MSc

Sue Armstrong, MSc

Christopher M. Feindel, MD
Objectives: This study was designed to determine the effects of age, coronary artery disease and other cardiac comorbidities on late outcome following bioprosthetic aortic valve replacement. Methods: Data were prospectively collected on 670 patients undergoing aortic valve replacement with the Hancock II bioprosthesis (Medtronic, Inc, Minneapolis, Minn) between 1982 and 1994. Mean patient age was $65 \pm 12$ years (median, 68 years; range, 18-86 years). Follow-up was 99.7\% complete at $69 \pm 40$ months (median, 66 months; range, 0.1-168 months). Survival and freedom from reoperation were evaluated univariately by KaplanMeier analysis and multivariably by Cox regression. Results: After adjustment for gender, Cox regression analysis revealed that age of 65 years or older, left ventricular dysfunction, the presence of coronary artery disease, and advanced New York Heart Association functional classification were associated with a higher risk of late death. At 12 years, survival was significantly different by Kaplan-Meier analysis for both age younger than 65 years $(71 \% \pm 4 \%)$ versus age 65 years or older $(36 \% \pm 7 \% ; P<.0001)$, left ventricular function grades 3 and $4(26 \% \pm$ $13 \%)$ versus grades 1 and $2(59 \% \pm 4 \% ; P<.0001)$, no coronary artery disease $(65 \% \pm 4 \%)$ versus coronary artery disease $(35 \% \pm 8 \% ; P<$ $.0001)$, and functional class IV $(33 \% \pm 9 \%)$ versus classes I to III $(62 \%$ $\pm 4 \% ; P<.0001)$. Only 9 patients experienced primary tissue failure, all of whom were younger than 65 years of age. At 12 years, the freedom from primary tissue failure was $84 \% \pm 4 \%$ for those patients younger than 65 years of age, and $100 \%$ for those 65 years of age or older $(P=$ .006). Conclusions: Long-term survival after aortic valve replacement is highly dependent on age, coronary artery disease, functional class, and left ventricular function, although bioprosthetic durability is dependent almost solely on age. Due to increased valve durability in patients who are 65 years of age or older, the Hancock II bioprosthesis may be an ideal aortic valve substitute in this age group. In patients who are younger than 65 years of age with advanced functional class, impaired left ventricular function, and coronary artery disease, this valve may also be used with a low probability of primary tissue failure. Patients without additional cardiac comorbidity may outlive their bioprosthetic valve, leading to reoperation. (J Thorac Cardiovasc Surg 1999;117:273-84)
A ortic valve replacement (AVR) is the treatment of choice for advanced aortic valve disease and currently accounts for $13 \%$ of all adult cardiac surgery in Ontario. ${ }^{1}$ Prolonged life span in a progressively aging

From the Division of Cardiovascular Surgery at The Toronto Hospital, and the University of Toronto, Toronto, Ontario, Canada.

Read at the Seventy-eighth Annual Meeting of The American Association for Thoracic Surgery, Boston, Mass, May 3-6, 1998

Received for publication May 8, 1998; revisions requested June 29, population is likely to increase the incidence of aortic valve disease and the demand for AVR in the future. Although patient preference and the risk of anticoagulation with warfarin sodium are often considered in select-

1998; revisions received Sept 15, 1998; accepted for publication Oct 7, 1998 .

Address for reprints: Tirone E. David, MD, The Toronto Hospital, EN13-219, 200 Elizabeth St, Toronto, Ontario M5G 2C4, Canada. Copyright @ 1999 by Mosby, Inc.

$0022-5223 / 99 \$ 8.00+0 \quad \mathbf{1 2 / 6 / 9 4 9 6 5}$ 
ing the most appropriate valvular prosthesis (tissue vs mechanical), predictors of survival are often overlooked. Matching patient survival to prosthetic durability is crucial in view of the increased morbidity and mortality rates associated with reoperative valvular procedures. ${ }^{2}$ Moreover, appropriate allocation of patients to a specific valve type may reduce valve-related complications and allow for improved quality of life.

Advanced age and concomitant coronary artery disease (CAD) have long been described as independent predictors of both early and late morbidity and death after AVR. ${ }^{3-7}$ This study defines both the independent and combined effects of these and other cardiac comorbid factors on long-term patient survival after bioprosthetic AVR.

\section{Methods}

Patients. Between September 1982 and December 1994 at The Toronto Hospital, 670 consecutive patients underwent isolated AVR with the Hancock II bioprosthesis (Medtronic, Inc, Minneapolis, Minn). Four cohorts of this patient population were constructed on the basis of the presence or absence of CAD and age above or below 65 years at the time of operation: (1) younger than 65 years of age without $\mathrm{CAD}(\mathrm{n}=$ 177), (2) younger than 65 years of age with $\operatorname{CAD}(n=77)$, (3) 65 years of age or older without CAD $(n=196)$, and (4) 65 years of age or older with $\mathrm{CAD}(\mathrm{n}=220)$.

All patients were entered prospectively into a hospital registry at the time of operation and were followed up prospectively thereafter. Follow-up was conducted by either clinic visit or telephone interview during a 4-month period that ended in December 1996. When patients could not be contacted via such methods, follow-up was obtained from a family physician. All events were verified by physician letter.

To minimize transvalvular gradients, attempts were made to match patient body surface area to bioprosthetic size with the use of guidelines based on the hemodynamic performance of the Hancock II bioprosthesis. ${ }^{8,9}$ To accomplish this, patch enlargement of the aortic anulus was necessary in 19\% of patients undergoing AVR. In general, patch enlargement enabled insertion of valves 1 to 2 sizes larger than would otherwise be possible without enlargement.

From 1982 to 1989, all patients undergoing bioprosthetic AVR at The Toronto Hospital were discharged from hospital on a regimen of daily warfarin sodium for the first 3 months after the operation. This practice was discontinued in 1990, after which time patients received only aspirin (325 mg once daily) after the operation.

Operative survivors underwent at least one echocardiographic evaluation during the first postoperative year and additional evaluations in the event of cardiac or valve-related complications. Postoperative complications were prospectively monitored and analyzed according to guidelines set forth by The American Association for Thoracic Surgery. ${ }^{10}$

Outcomes. The primary outcome for this paper was to define all causes of death. Cause of death was established from hospital records or autopsy reports. We also evaluated operative death, defined as any in-hospital death.

Bioprosthetic valve dysfunction was a secondary outcome. Bioprosthetic valve dysfunction was defined as any clinically relevant valvular stenosis or insufficiency documented by Doppler echocardiography, reoperation, or autopsy. All 9 patients with valve dysfunction had primary tissue failure (PTF) and underwent successful redo surgery within 1 to 9 weeks of the diagnosis of PTF. For the purpose of these analyses, the date of operation was considered the failure date for PTF. Because not all patients had undergone echocardiographic evaluation by the time of the last follow-up contact, the time to PTF may have been slightly over-estimated.

Additional outcomes included thromboembolic events (the first event was included in analyses but not subsequent events), bioprosthetic valve endocarditis, and repeat AVR.

Variables. The preoperative variables tested for their univariate and multivariable association with the outcomes included age, gender, New York Heart Association (NYHA) classification, left ventricular grade (1, ejection fraction $>60 \% ; 2$, ejection fraction $40 \%-60 \%$; 3 , ejection fraction $20 \%-39 \%$; 4 , ejection fraction $<20 \%$ ), preoperative echocardiographic rhythm (sinus, atrial fibrillation/flutter, heart block), endocarditis, CAD, type of aortic valve lesion, and previous cardiac operation. After a careful examination of the univariate results, we collapsed 2 ordinal variables into dichotomous variables: symptoms at rest (NYHA class IV vs NYHA classes I, II, or III), and left ventricular dysfunction (left ventricular grades 3 and 4 vs left ventricular grades 1 and 2). As stated previously, age was collapsed into a dichotomous variable, namely younger than 65 years of age or 65 years of age and older.

Statistical analyses. The SAS and BMDP programs (SAS Institutes, Inc, Cary, NC; BMPD Software, Los Angeles, Calif) were used for statistical analyses. Continuous variables are presented as the mean \pm standard deviation in the text and as the mean \pm standard error in tables and figures, unless otherwise noted.

Univariate. After a careful examination of the results of univariate analyses and previously published reports, we chose 65 years of age as a cut-off point for the construction of 4 cohorts based on age and the presence or absence of CAD. Differences in prognostic variables between the cohorts were evaluated by analysis of variance for continuous variables and $\chi^{2}$ or Fisher's exact test for categoric variables.

Time-related data such as survival, freedom from thromboembolic events, freedom from reoperation, freedom from PTF, or combined valve-related events were analyzed univariately by the Kaplan-Meier (or product limit) test.

Multivariable. Operative death was analyzed multivariably by logistic regression analysis. Late survival was evaluated multivariably in the entire study population, by Cox regression analysis, and an accelerated time failure analysis by the use of log-logistic regression. For both multivariable models the same model-building strategy was used: those variables that had a univariate $P$ value $<.25$ or those of known biologic 
Table I. Clinical characteristics of all patients by group

\begin{tabular}{|c|c|c|c|c|c|}
\hline Characteristic & $\begin{array}{c}<65 y / n o C A D \\
(n=177)\end{array}$ & $\begin{array}{c}<65 y / \text { with } C A D \\
(n=77)\end{array}$ & $\begin{array}{c}\geq 65 y / n o C A D \\
\quad(n=196)\end{array}$ & $\begin{array}{c}\geq 65 y / \text { with } C A D \\
(n=220)\end{array}$ & $\mathrm{P}$ value \\
\hline Follow-up (mo; mean $\pm \mathrm{SD}$ ) & $82 \pm 43$ & $80 \pm 43$ & $67 \pm 36$ & $56 \pm 35$ & .0001 \\
\hline Age $(y ;$ mean \pm SD) & $51 \pm 11$ & $59 \pm 7$ & $72 \pm 5$ & $73 \pm 4$ & .0001 \\
\hline \multicolumn{6}{|l|}{ Gender (No.) } \\
\hline Male $(\%)$ & $131(74)$ & $68(88)$ & $127(65)$ & $179(81)$ & \\
\hline Female $(\%)$ & $46(26)$ & $9(12)$ & $69(35)$ & $41(19)$ & .001 \\
\hline \multicolumn{6}{|l|}{ NYHA class (No.) } \\
\hline $\mathrm{I}(\%)$ & $15(9)$ & 0 & $3(2)$ & $1(1)$ & \\
\hline II (\%) & $66(37)$ & $22(29)$ & $34(17)$ & $35(16)$ & \\
\hline III (\%) & $55(31)$ & $33(42)$ & $98(50)$ & $100(45)$ & \\
\hline $\mathrm{IV}(\%)$ & $41(23)$ & $22(29)$ & $61(31)$ & $84(38)$ & .001 \\
\hline \multicolumn{6}{|l|}{ Left ventricular grade (No.) } \\
\hline 1. $\mathrm{EF}>0.60(\%)$ & $50(34)$ & $9(14)$ & $53(32)$ & $45(23)$ & \\
\hline 2. EF $0.40-0.60(\%)$ & $69(48)$ & $33(52)$ & $73(43)$ & $96(49)$ & \\
\hline 3. EF $0.20-0.39(\%)$ & $19(13)$ & $17(27)$ & $33(20)$ & $46(23)$ & \\
\hline 4. $\mathrm{EF}<0.20(\%)$ & $7(5)$ & $4(6)$ & $8(5)$ & $9(5)$ & .58 \\
\hline \multicolumn{6}{|l|}{ Rhythm before operation (No.) } \\
\hline Normal sinus rhythm (\%) & $170(96)$ & $74(96)$ & $167(85)$ & $188(86)$ & \\
\hline Atrial fibrillation (\%) & $5(3)$ & $2(3)$ & $19(10)$ & $25(11)$ & \\
\hline Complete heart block (\%) & $2(1)$ & $1(1)$ & $10(5)$ & $7(3)$ & .001 \\
\hline \multicolumn{6}{|l|}{ Endocarditis } \\
\hline Remote $(\%)$ & $6(3)$ & $1(1)$ & $1(0.5)$ & $3(1)$ & \\
\hline Active $(\%)$ & $11(6)$ & $3(4)$ & $5(3)$ & $5(3)$ & .004 \\
\hline \multicolumn{6}{|l|}{$\mathrm{CAD}$} \\
\hline Single vessel (\%) & - & $17(22)$ & - & $66(30)$ & \\
\hline Double vessel (\%) & - & $26(34)$ & - & $73(33)$ & \\
\hline Triple vessel (\%) & - & $34(44)$ & - & $81(37)$ & .001 \\
\hline \multicolumn{6}{|l|}{ Aortic valve lesion } \\
\hline Stenosis $(\%)$ & $51(29)$ & $35(45)$ & $94(48)$ & $136(62)$ & \\
\hline Insufficiency (\%) & $70(39)$ & $23(30)$ & $39(20)$ & $27(12)$ & \\
\hline Mixed $(\%)$ & $56(32)$ & $19(25)$ & $63(32)$ & $57(26)$ & .001 \\
\hline \multicolumn{6}{|l|}{ Previous cardiac operation (\%) } \\
\hline Aortic valve repair (\%) & $7(4)$ & 0 & 0 & 0 & \\
\hline $\operatorname{AVR}(\%)$ & $11(6)$ & $1(1)$ & $20(10)$ & $13(6)$ & \\
\hline Mitral valve repair (\%) & 0 & 0 & $1(0.5)$ & 0 & \\
\hline $\operatorname{CABG}(\%)$ & $1(1)$ & $4(5)$ & $3(2)$ & $12(5)$ & .001 \\
\hline \multicolumn{6}{|l|}{ Coronary artery bypass } \\
\hline One $(\%)$ & - & $16(21)$ & - & $65(30)$ & \\
\hline Two $(\%)$ & - & $21(27)$ & - & $65(30)$ & \\
\hline Three (\%) & - & $26(33)$ & - & $65(30)$ & \\
\hline Four $(\%)$ & - & $13(17)$ & - & $17(8)$ & \\
\hline Five $(\%)$ & - & $1(2)$ & - & $3(2)$ & .26 \\
\hline \multicolumn{6}{|l|}{ AVR-Hancock II } \\
\hline $21 \mathrm{~mm}(\%)$ & $6(3)$ & $4(5)$ & $20(10)$ & $18(8)$ & \\
\hline $23 \mathrm{~mm}(\%)$ & $29(16)$ & $16(21)$ & $75(38)$ & $78(36)$ & \\
\hline $25 \mathrm{~mm}(\%)$ & $49(28)$ & $22(29)$ & $54(28)$ & $83(38)$ & \\
\hline $27 \mathrm{~mm}(\%)$ & $71(40)$ & $29(38)$ & $38(19)$ & $36(16)$ & \\
\hline $29 \mathrm{~mm}(\%)$ & $22(12)$ & $6(8)$ & $9(5)$ & $5(2)$ & .001 \\
\hline Patch enlargement (\%) & $37(21)$ & $9(12)$ & $38(19)$ & $41(19)$ & .373 \\
\hline Crossclamp time (min) & $64 \pm 25$ & $81 \pm 23$ & $62 \pm 24$ & $87 \pm 24$ & .0001 \\
\hline Cardiopulmonary bypass time (min) & $86 \pm 33$ & $108 \pm 32$ & $84 \pm 20$ & $120 \pm 34$ & .0001 \\
\hline
\end{tabular}

$E F$, Ejection fraction.

importance but failing to meet the critical alpha level were submitted for consideration to the models by the use of stepwise selection.

Regression coefficients from an accelerated time failure model by the log-logistic distribution were used to calculate the predicted probability of survival at specific time periods from the formula:

$$
\mathrm{S}(\mathrm{t} \mid \mathrm{X})=1 / 1+\left\{e^{-\mathrm{g}\left(\beta_{\mathrm{o}}+\beta 1 \mathrm{X} 1 \ldots .+\beta \mathrm{nXn}\right)} \cdot \mathrm{t}^{\mathrm{g}}\right\}
$$

where $S=$ survival probability, $g=1 /$ scale, $\beta=$ regression coefficient, $\mathrm{X}=$ covariate, $\mathrm{t}=$ follow-up time (months). 
Table II. Operative death and morbidity

\begin{tabular}{|c|c|c|c|c|c|}
\hline Characteristic (No.) & $\begin{array}{c}<65 y / n o C A D \\
(n=177)\end{array}$ & $\begin{array}{c}<65 y / \text { with } C A D \\
(n=77)\end{array}$ & $\begin{array}{c}\geq 65 y / n o C A D \\
(n=96)\end{array}$ & $\begin{array}{c}\geq 65 y / \text { with } C A D \\
\quad(n=220)\end{array}$ & $\mathrm{P}$ value \\
\hline Hospital deaths (\%) & $6(3)$ & $5(7)$ & $5(3)$ & $16(7)$ & .165 \\
\hline \multicolumn{6}{|l|}{ Early reoperation } \\
\hline Bleed $(\%)$ & $8(5)$ & $4(5)$ & $10(5)$ & $16(7)$ & \\
\hline Tamponade (\%) & 0 & 0 & $1(0.5)$ & $4(2)$ & \\
\hline Arrest $(\%)$ & 0 & 0 & 0 & $1(0.5)$ & \\
\hline Sternal infection $(\%)$ & 0 & 0 & 0 & $3(1)$ & \\
\hline Sternal dehiscence (\%) & $1(0.5)$ & 0 & 0 & $1(0.5)$ & \\
\hline Other $(\%)$ & $1(0.5)$ & 0 & 0 & $1(0.5)$ & .067 \\
\hline Perioperative MI (\%) & $4(2)$ & $1(1)$ & $2(1)$ & $2(1)$ & .238 \\
\hline Postoperative pacing* $\left.{ }^{*} \%\right)$ & $8(5)$ & $1(1)$ & $13(7)$ & $19(9)$ & .042 \\
\hline Stroke $(\%)$ & $3(2)$ & 0 & $5(3)$ & $14(6)$ & .006 \\
\hline Sternal infection $(\%)$ & 0 & $1(1)$ & $1(0.5)$ & $7(3)$ & .012 \\
\hline Other wound infection (\%) & $1(0.5)$ & 0 & $2(1)$ & $3(1)$ & .317 \\
\hline
\end{tabular}

MI, Myocardial infarction.

*Postoperative permanent pacemaker requirement.

Table III. Late death and morbidity

\begin{tabular}{|c|c|c|c|c|}
\hline Characteristic (No.) & $\begin{array}{c}<65 y / n o C A D \\
(n=177)\end{array}$ & $\begin{array}{c}<65 y / \text { with } C A D \\
(n=77)\end{array}$ & $\begin{array}{c}\geq 65 y / n o C A D \\
\quad(n=196)\end{array}$ & $\begin{array}{c}\geq 65 y / \text { with } C A D \\
\quad(n=220)\end{array}$ \\
\hline Late deaths ${ }^{*}(\%)$ & $25(14)$ & $17(22)$ & $42(21)$ & $62(28)$ \\
\hline \multicolumn{5}{|l|}{ Causes of late death (\%) } \\
\hline Valve-related deaths ${ }^{\dagger}(\%)$ & $5(3)$ & 0 & $5(3)$ & $7(3)$ \\
\hline Cardiac (nonvalve related) $)^{\ddagger}(\%)$ & $10(6)$ & $8(11)$ & $19(10)$ & $22(10)$ \\
\hline Noncardiac/nonvalve $(\%)$ & $10(6)$ & $9(12)$ & $18(9)$ & $33(15)$ \\
\hline PTF (\%) & $5(3)$ & $4(5)$ & 0 & 0 \\
\hline \multicolumn{5}{|l|}{ Thromboembolism (\%) } \\
\hline New stroke $(\%)$ & $2(1)$ & $1(1)$ & $14(7)$ & $14(6)$ \\
\hline New TIA (\%) & $4(2)$ & $2(3)$ & $4(2)$ & $5(2)$ \\
\hline Reoperation at follow-up (\%) & $12(7)$ & $4(5)$ & $2(1)$ & $4(2)$ \\
\hline Prosthetic valve endocarditis (\%) & $7(4)$ & 0 & $4(2)$ & $6(3)$ \\
\hline Valve-related morbidity $(\%)$ & $22(12)$ & $8(10)$ & $22(11)$ & $27(12)$ \\
\hline Valve-related $\mathrm{M}+\mathrm{M}^{\|}(\%)$ & $48(27)$ & $29(38)$ & $58(30)$ & $95(43)$ \\
\hline
\end{tabular}

*All deaths, excluding hospital deaths.

'Death from valve failure, cerebrovascular event, or prosthetic valve endocarditis.

Death from ischemic heart disease, congestive heart failure, or sudden death.

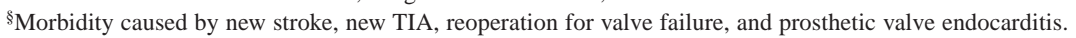

"Morbidity or death from valve-related factors.

Table IV. Cox regression model for survival

\begin{tabular}{lcc}
\hline Variable & $\begin{array}{c}\text { Regression } \\
\text { coefficient } \pm S E\end{array}$ & Risk ratio \\
\hline CAD & $0.4297 \pm 0.158$ & 1.54 \\
Age \pm 65 years & $0.5383 \pm 0.171$ & 1.71 \\
$\begin{array}{l}\text { Left ventricular dysfunction } \\
\quad \text { grades 3 and 4) }\end{array}$ & $0.3981 \pm 0.173$ & 1.49 \\
$\begin{array}{l}\text { Symptoms at rest } \\
\text { (NYHA, grade 4) }\end{array}$ & $0.5851 \pm 0.160$ & 1.80 \\
\begin{tabular}{l} 
Male gender \\
\hline
\end{tabular} & $0.3719 \pm 0.199$ & 1.45 \\
\hline
\end{tabular}

\section{Results}

Patients and follow-up. Table I summarizes the clinical and operative data of all patients by cohort. Although the 670 operative procedures were divided among 11 surgeons, 2 surgeons performed almost three fourths of the operations (493 AVRs; 74\%). Patients with significant $\mathrm{CAD}$ on preoperative angiography underwent a concomitant coronary artery bypass graft operation (CABG). Twenty-seven percent of patients underwent previous AVR or repair; $13 \%$ of patients underwent previous $\mathrm{CABG}$.

Follow-up of all patients was $99.7 \%$ complete at a mean follow-up time of $69 \pm 40$ months (median, 66 months; range, $0.1-168$ months), with $75 \%$ of patients providing follow-up of at least 93 months. Two patients were lost to follow-up, both of whom were younger than 65 years of age and only one of whom had concomitant CAD. Mean patient age was $65 \pm 12$ years (median, 68 years; range, 18-86 years). Mean body sur- 
Table V. Survival probability calculated from the accelerated time failure model with the log-logistic distribution for combinations of risk factors

\begin{tabular}{|c|c|c|c|c|c|}
\hline$C A D$ & Age $\geq 65 y$ & $\begin{array}{l}\text { NYHA } \\
\text { grade IV }\end{array}$ & $\begin{array}{l}\text { Left ventricular } \\
\text { grades } 3 \text { or } 4\end{array}$ & $\begin{array}{c}\text { Predicted survival } \\
\text { at } 5 y(\%)\end{array}$ & $\begin{array}{c}\text { Predicted survival } \\
\text { at } 10 y(\%)\end{array}$ \\
\hline & & & & $89.1(73,100)$ & $83.9(73,95)$ \\
\hline \multirow[t]{4}{*}{$\checkmark$} & & & & $83.4(70,97)$ & $76.2(67,85)$ \\
\hline & $\checkmark$ & & & $84.5(71,98)$ & $77.7(69,86)$ \\
\hline & & $\checkmark$ & & $83.6(70,97)$ & $76.6(68,85)$ \\
\hline & & & $\checkmark$ & $82.3(69,96)$ & $74.8(66,84)$ \\
\hline$\checkmark$ & $\checkmark$ & & & $77.1(66,88)$ & $68.2(61,75)$ \\
\hline$\checkmark$ & & $\checkmark$ & & $75.9(65,87)$ & $66.8(60,74)$ \\
\hline \multirow[t]{4}{*}{$\checkmark$} & & & $\checkmark$ & $74.1(63,85)$ & $64.6(58,72)$ \\
\hline & $\checkmark$ & $\checkmark$ & & $77.4(66,88)$ & $68.6(62,76)$ \\
\hline & $\checkmark$ & & $\checkmark$ & $75.7(65,86)$ & $66.5(59,74)$ \\
\hline & & $\checkmark$ & $\checkmark$ & $74.5(64,85)$ & $65.1(58,72)$ \\
\hline$\checkmark$ & $\checkmark$ & $\checkmark$ & & $67.8(59,77)$ & $57.4(52,63)$ \\
\hline \multirow[t]{2}{*}{$\checkmark$} & $\checkmark$ & & $\checkmark$ & $65.7(57,75)$ & $55.0(49,61)$ \\
\hline & $\checkmark$ & $\checkmark$ & $\checkmark$ & $66.2(57,75)$ & $55.5(50,61)$ \\
\hline$\checkmark$ & $\checkmark$ & $\checkmark$ & $\checkmark$ & $54.6(47,62)$ & $43.5(39,48)$ \\
\hline
\end{tabular}

Each of these 4 risk factors was entered into the model as a dichotomous variable (ie, NYHA IV versus NYHA I, II, or III; left ventricular grades 3 or 4 versus left ventricular grades 1 or 2 ). The check mark $(\checkmark)$ indicates the risk factor is present. These 4 risk factors are not present for the first row of estimates. The upper and lower $95 \% \mathrm{CI}$ for the predicted survival probabilities are given in parentheses.

face area was $1.81 \pm 0.29 \mathrm{~m}^{2}$ (median, $1.84 \mathrm{~m}^{2}$; range, 1.5-2.6 $\mathrm{m}^{2}$ ). Age and duration of follow-up by group are presented in Table I.

Operative mortality and morbidity. Table II shows the operative mortality and morbidity rates in all patients by group. All but 6 patients with CAD on preoperative angiogram underwent concomitant CABG. Among these 6 patients who did not undergo revascularization, 3 patients were alive at late follow-up, and 3 patients died at a mean of $41 \pm 9$ months after having survived their initial operation. Logistic regression analysis revealed both CAD (odds ratio, 2.1; 95\% confidence interval $[\mathrm{CI}], 0.9-4.8)$ and advanced NYHA functional class IV (odds ratio, 3.1; 95\% CI, 1.4-6.9) to be associated with an increased risk of operative death.

Late death and morbidity. A summary of the causes of late death and morbid events is shown in Table III. There were 146 late deaths (22\%). The first Cox proportional hazard analysis of the entire data set revealed that active endocarditis, age 65 years or more, NYHA class IV, left ventricular grades 3 or 4 , the presence of $\mathrm{CAD}$, and male gender were predictive of late death. However, all deaths secondary to active endocarditis occurred during the early postoperative period; and because of the small number of patients with active endocarditis, this variable was excluded from subsequent multivariable analyses. After controlling for gender, the independent predictors of late survival by Cox regression were the presence of CAD, age ( $\geq 65$ years), left ventricular dysfunction, and symptoms at rest (Table IV). The global $\chi^{2}$ for this analysis was $63.78, P<.0001$.
The regression coefficients \pm standard errors and $P$ values for the accelerated time failure model with the use of the log-logistic distribution are given as follows: intercept $(7.3346 \pm 0.395 ; P=.0001)$, presence of CAD $(-0.7485 \pm 0.3138 ; P=.0171)$, age of 65 years or older $(-0.6192 \pm 0.3387 ; P=.0675)$, NYHA functional class IV $(-0.718 \pm 0.3289 ; P=.029)$, and left ventricular dysfunction $(-0.8666 \pm 0.3336 ; P=.0094)$. The scale factor was $1.5457 \pm 0.121$. Table $V$ shows the predicted probability of survival at 5 and 10 years, calculated by the log-logistic model for combinations of dichotomized risk factors.

The actuarial survival for all patients was $54 \% \pm 4 \%$ at 12 years $(62 \% \pm 9 \%$ in female patients and $51 \% \pm$ $5 \%$ in male patients; $P=.017$ ). Figs $1,2,3$, and 4 demonstrate the effect of age, functional class, left ventricular function, and CAD, respectively, on long-term survival. The combined effect of age and CAD on patient survival is shown in Fig 5.

PTF. Bioprosthetic valve dysfunction caused by PTF occurred in 9 patients, all of whom were younger than 65 years of age $(<65$ years of age without CAD, 5 patients; $<65$ years of age with CAD, 4 patients; Table III). The mean time to reoperation for the valves that failed was $87 \pm 28$ months (7.25 years; median, 87.5 months; range, 37-122 months). All patients with PTF underwent successful reoperations within 9 weeks of diagnosis of valve dysfunction. As seen in Fig 6, there was no PTF in patients who were 65 years of age or older, regardless of CAD status.

Thromboembolic events. There were a total of 46 


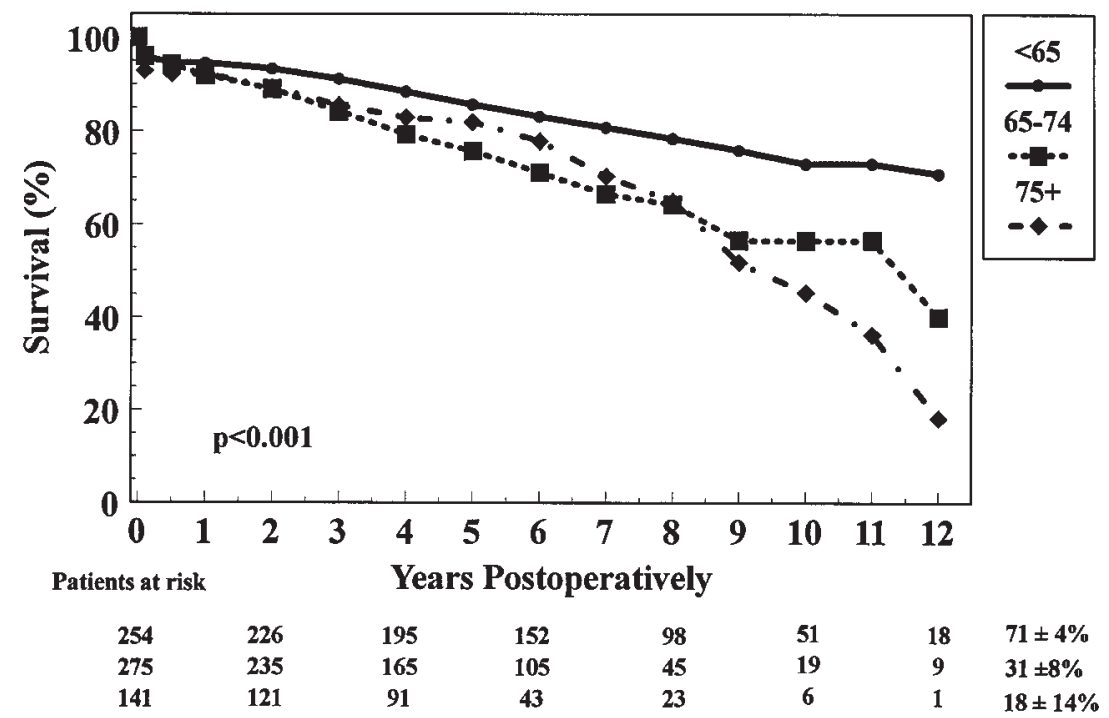

Fig 1. Influence of age on late survival after AVR: Actuarial survival was significantly decreased for patients who were 65 years of age or older in comparison with patients who were younger than 65 years of age, irrespective of CAD status $(P<.001)$.

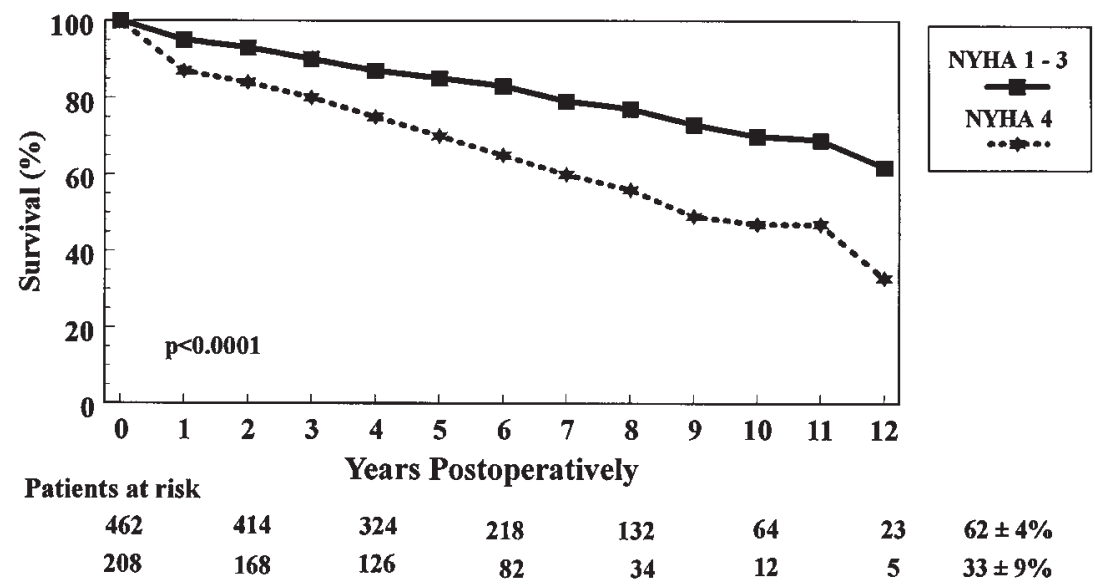

Fig 2. Influence of preoperative NYHA class on late survival after AVR: Patients in NYHA classes I to III before the operation demonstrated the best long-term survival, and patients in NYHA class IV demonstrated the poorest long-term survival $(P<.0001)$.

late thromboembolic events (32 strokes; 14 transient ischemic attacks [TIAs]), all of which represented primary events. Seven of the strokes were fatal $(<65$ years of age without CAD, 1 patient; <65 years of age with CAD, 0 patients; $\geq 65$ years of age without CAD, 3 patients; $\geq 65$ years of age with CAD, 3 patients). The actuarial freedom from thromboembolic events at 12 years was $94 \% \pm 2 \%$ in patients who were younger than 65 years of age without CAD, 93\% $\pm 3 \%$ in patients who were younger than 65 years of age with $\mathrm{CAD}, 82 \% \pm 5 \%$ in patients who were 65 years of age or older without $\mathrm{CAD}$, and $64 \% \pm 13 \%$ in patients who were 65 years of age or older with CAD $(P=.0127)$. Cox regression analysis revealed that age 65 years or older and the presence of concomitant CAD were associated with an increased incidence of thromboembolic complications. The absence of aspirin was also associated with an increased incidence of thromboembolic events, although information regarding aspirin use was incomplete.

Bioprosthetic valve endocarditis. Bioprosthetic valve endocarditis developed in 17 patients $(<65$ years 


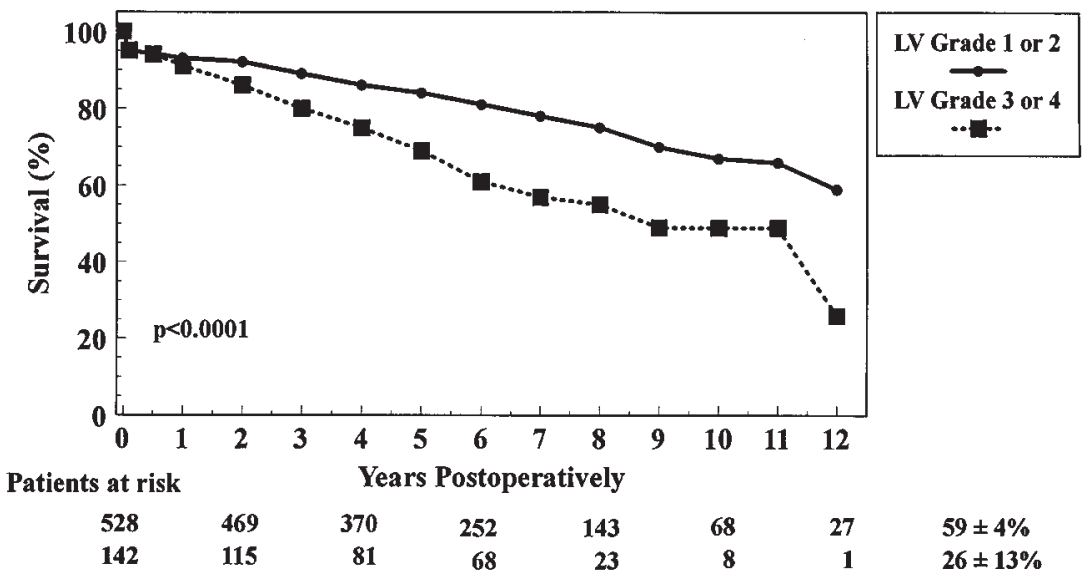

Fig 3. Influence of preoperative left ventricular grade on late survival after AVR: Actuarial survival was significantly decreased for patients with preoperative left ventricular grades 3 or 4 in comparison with patients with left ventricular grades 1 or $2(P<.0001)$.

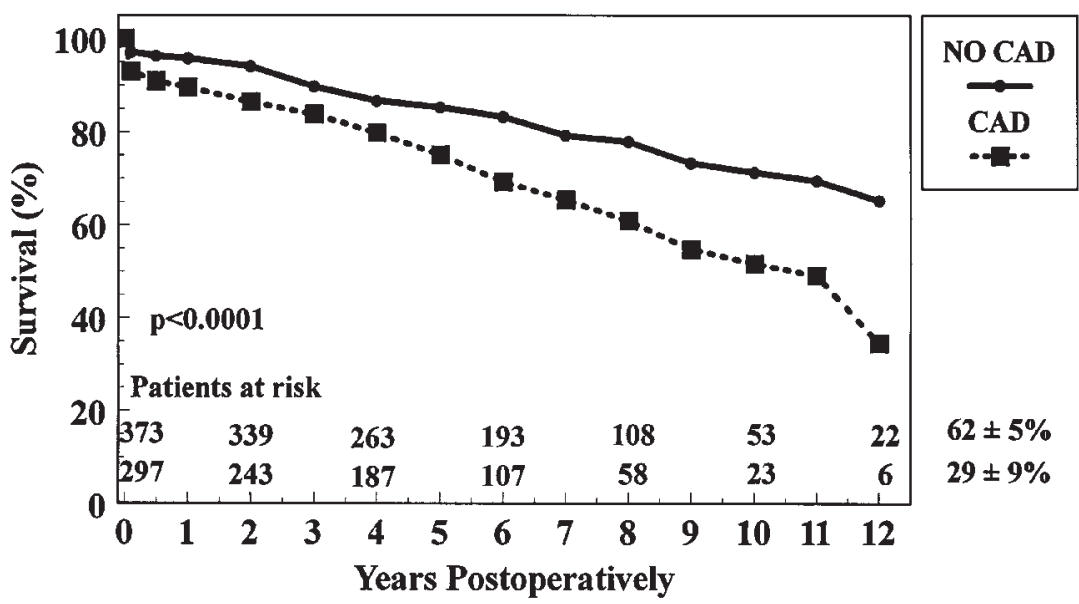

Fig 4. Influence of CAD on late survival after AVR: Actuarial survival was significantly decreased for patients with $\mathrm{CAD}$ in comparison with patients without $\mathrm{CAD}$, irrespective of age $(P<.0001)$.

of age without CAD, 7 patients; $<65$ years of age with CAD, 0 patients; $\geq 65$ years of age without CAD, 4 patients; $\geq 65$ years of age with CAD, 6 patients). Antibiotic therapy along with reoperation was undertaken in 7 of these patients, all of whom survived. The remaining 10 patients, none of whom survived, received antibiotic therapy only. The actuarial freedom from endocarditis at 12 years was $93 \% \pm 2 \%$ in patients who were younger than 65 years of age without CAD, 99\% $\pm 1 \%$ in patients who were younger than 65 years of age with CAD, $98 \% \pm 1 \%$ in patients who were 65 years of age or older without CAD, and $83 \% \pm 13 \%$ in patients who were 65 years of age or older with CAD $(P=.543)$.

Repeat AVR. Twenty-two patients were found to have undergone repeat AVR at the time of follow-up (Table III). The rate of reoperation was significantly higher in the younger age group ( $<65$ years of age), irrespective of CAD status. The indications for reoperation included aortic dissection (1 patient), increased left ventricular outflow tract gradient with a normally functioning valve (1 patient), periprosthetic leakage (3 patients), PTF (9 patients), prosthetic valve endocarditis (7 patients), and recurrent TIA (1 patient). Only one patient undergoing reoperation for periprosthetic leakage died during the operation. The actuarial freedom from reoperation at 12 years was $82 \% \pm 6 \%$ in patients who were younger than 65 years of age without CAD, $88 \% \pm 6 \%$ in patients who were younger than 65 years 


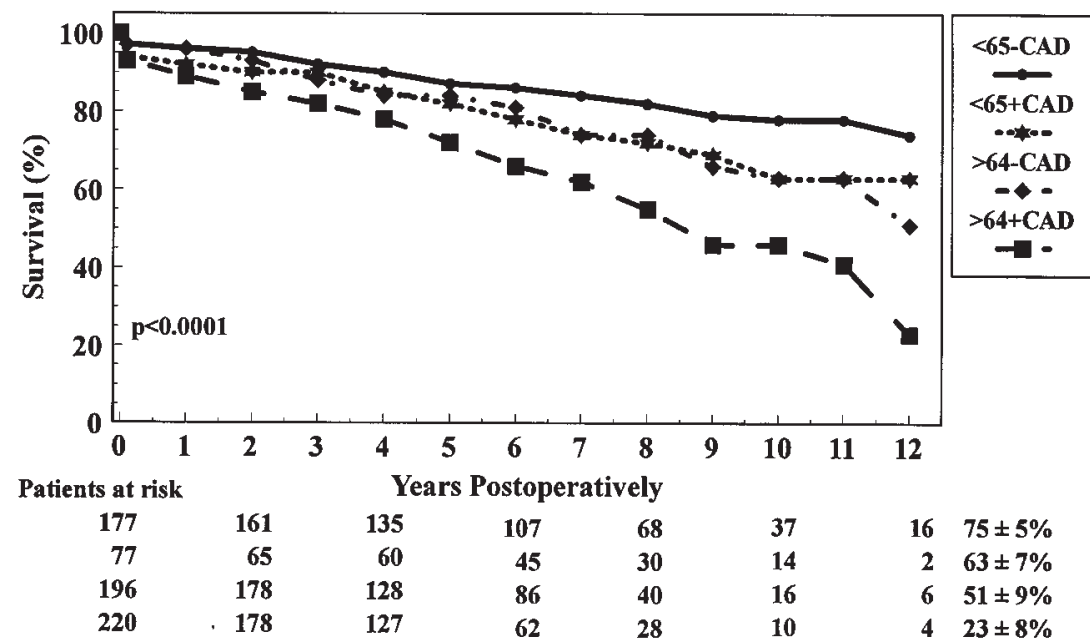

Fig 5. Combined influence of age and CAD on late survival after AVR: Patients who were younger than 65 years of age with no CAD demonstrated the best long-term survival, patients who were younger than 65 years of age with CAD or patients who were 65 years of age or older without CAD demonstrated intermediate long-term survival, and patients who were 65 years of age or older with CAD demonstrated the poorest long-term survival $(P$ $<.0001)$.

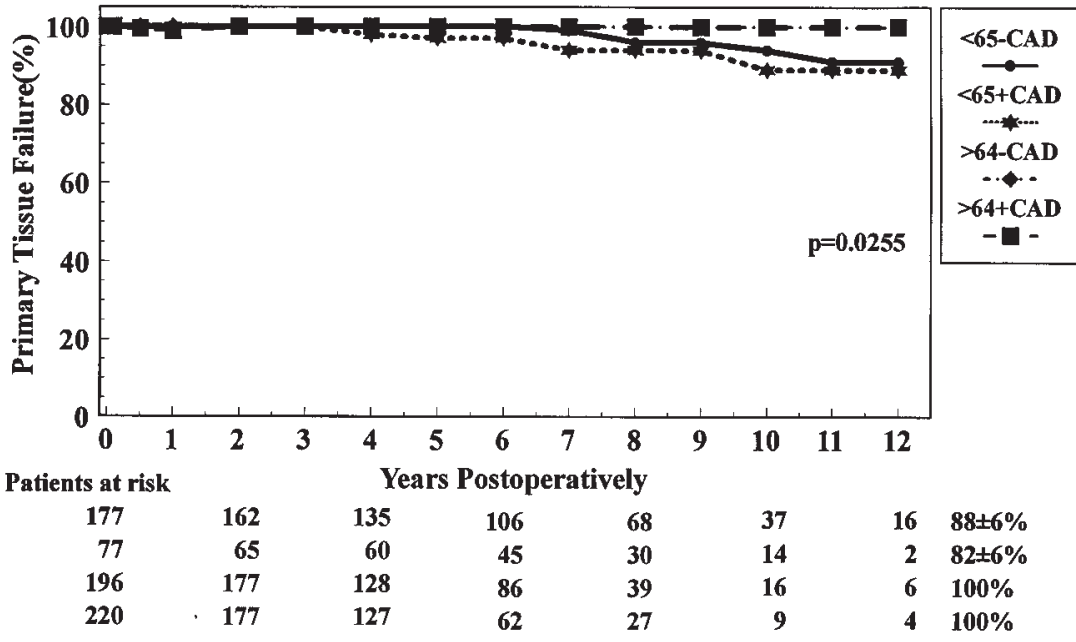

Fig 6. Combined influence of age and CAD on freedom from PTF after AVR: Actuarial freedom from PTF was significantly decreased for patients who were younger than 65 years of age in comparison with patients who were 65 years of age or older, irrespective of CAD status $(P=.0255)$.

of age with $\mathrm{CAD}, 99 \% \pm 1 \%$ in patients who were 65 years of age or older without CAD, and $98 \% \pm 1 \%$ in patients who were 65 years of age or older with CAD $(P=.045)$. Cox regression analysis revealed only age 65 years or younger to be predictive of reoperation (risk ratio, $2.9 ; 95 \% \mathrm{CI}, 1.1-7.5)$.

\section{Discussion}

It remains difficult to match the patient requiring AVR to the appropriate prosthetic heart valve. Mechan- ical valves are more durable than bioprosthetic valves but necessitate permanent oral anticoagulation and are associated with a constant risk of bleeding and thromboembolic complications. ${ }^{11,12}$ Bioprosthetic heart valves are less thrombogenic than mechanical valves and do not require oral anticoagulation. However, because of limited durability, reoperation may be necessary in patients who outlive the valves. ${ }^{12}$ Thus in addition to considering patient preference and their ability to take oral anticoagulants, surgeons must aim 
to optimize the quality of life and minimize the risk of death and morbidity when counseling their patients who require AVR.

This study was designed to evaluate factors that may affect long-term survival after AVR with the Hancock II bioprosthesis, a heart valve that has been used at our institution since $1982 .{ }^{8,13} \mathrm{We}$ also analyzed the risk of valve-related complications in this population.

After careful analysis of our data, we found the following preoperative cardiac comorbid conditions to be associated with increased risk of late death after AVR: symptoms at rest (risk ratio, 1.80), age 65 years or older (risk ratio, 1.71), CAD (risk ratio, 1.54), left ventricular ejection fraction less than $40 \%$ (risk ratio, 1.49), and male gender (risk ratio, 1.45). Age was the only factor that affected bioprosthetic durability in this study. There were no cases of PTF at 12 years in patients older than 65 years of age. Age 65 years or older and CAD were associated with a higher risk of thromboembolic complications.

Although age was not an independent predictor of operative death in our study, it had a significant effect on late death as shown in Fig 1 and in previous studies. ${ }^{4-6,14-16}$ Male gender was similarly found to have a negative effect on long-term survival, an observation previously described by $\mathrm{He}$ and colleagues. ${ }^{15}$

Advanced functional status (NYHA functional class IV) has been identified as an important prognostic variable for operative death in numerous studies. $3,5,11,14$ Our study demonstrates an increased risk of death after the operation in this patient sample. In fact, NYHA class IV was the most powerful predictor of death after AVR in our series, as shown in Fig 2.

Left ventricular function has also been identified as a risk factor for death both early and late after AVR. ${ }^{4}$ In our series, there was a significant difference in 12-year survival for patients with ejection fractions below $40 \%$ versus those with ejection fractions above $40 \%$, as shown in Fig 3.

The presence of CAD at the time of operation was found to have an independent effect on late death (Fig 4). At 12 years, the best overall survival was demonstrated by younger patients without CAD, and the worst survival was in older patients with CAD (Fig 5). Younger patients with CAD and older patients without CAD demonstrated similar survival after AVR. Several studies have similarly documented the adverse effect of CAD in AVR. ${ }^{6,14,16}$ In a review by Jones and colleagues, ${ }^{6}$ which included both mechanical and prosthetic valves, age and CAD were shown to have a significant impact on both early and late patient survival after AVR. The 10-year actuarial survival after AVR was $60 \%$ in patients without CAD and $39 \%$ in those with
CAD. The negative effect of CAD was evident in every age group. ${ }^{6}$

Late survival after AVR was dependent on multiple factors in our series. Because none of these factors should be viewed in isolation, we estimated the 5- and 10-year actuarial survival using a log-logistic model shown in Table V. Thus the predicted 10-year survival after AVR ranged from approximately $84 \%$ (patients who were younger than 65 years of age without any cardiac comorbid conditions) to $43 \%$ (patients who were 65 years of age or older with CAD, NYHA class IV, and left ventricular ejection fraction below 40\%). We provide Table $\mathrm{V}$ as an interesting tool that may be useful to estimate patient survival by the probability of bioprosthetic valve failure.

PTF represents the major limitation to bioprosthetic heart valves. Age and valve position have been shown to be important determinants of valve longevity with increased prosthetic durability in the aortic position and in older patients where hemodynamic stresses may be minimized. ${ }^{17-19}$ Burr and colleagues ${ }^{19}$ found that freedom from PTF after AVR with the CarpentierEdwards porcine bioprosthesis was $98 \%$ for patients 65 to 69 years of age at 15 years after implantation, $95 \%$ for patients 70 to 79 years of age at 13 years after implantation, and $100 \%$ for patients 80 years of age or older at 13 years after implantation.

In the current study, only 9 cases of PTF were demonstrated, all of which occurred in patients younger than 65 years of age. Thus freedom from PTF in patients 65 years of age or older was $100 \%$ at 12 years.

Although our study suggested a number of predictors for late outcome, the inherent limitations are those that apply to any observational outcomes analysis. The possibility of significant residual and unmeasured confounding variables remains a concern. Moreover, the generalizability of the regression model is threatened by both patient selection and a relatively small sample size with small numbers of events. It is likely that several more independent predictors of survival could have been identified with a larger sample size and/or more adverse events. These results merely illustrate the continued dilemma faced by cardiac surgeons in their attempt to select the most appropriate valvular prosthesis for AVR on the basis of predictors of outcome.

\section{Conclusions}

Long-term survival after AVR with a bioprosthetic valve is highly dependent on premorbid conditions such as age, ventricular function, CAD, and functional class, none of which should be viewed in isolation. By analyzing the combined effects of these important variables on patient outcome and bioprosthetic valve dura- 
bility, guidelines for valve selection can be successfully formulated in most cases. In consideration of these factors, we have developed the following inferences regarding the use of bioprosthetic valves for AVR:

Age younger than 65 years without CAD: Patient survival is likely to exceed tissue valve durability. Thus reoperations for PTF will likely become necessary.

Age younger than 65 years with CAD: The negative impact of age on bioprosthetic durability in the younger aged groups was far more significant than the negative impact of CAD on survival in the same groups. Thus reoperation as the result of PTF must also be considered in such patients.

Age 65 years or older without CAD: Although survival in patients who are older than 65 years of age without CAD was similar to that of patients who were younger than 65 years of age with $\mathrm{CAD}$, bioprosthetic valves were more durable in this age group. Thus patients who are 65 years of age or older without CAD are less likely to outlive their bioprosthetic valves.

Age 65 years or older with CAD: The markedly decreased survival in patients who are 65 years of age or older with $\mathrm{CAD}$, along with the age-related increase in tissue valve durability may make a bioprosthesis ideal in such patient subgroups.

NYHA class IV or left ventricular grades 3,4: Because of the markedly decreased life expectancy, bioprosthetic valves may be appropriate for these patients.

\section{REFERENCES}

1. Morgan CD, Sykora K, Naylor CD, and the Steering Committee of the Cardiac Care Network of Ontario. Analysis of deaths while waiting for cardiac surgery in 29,293 consecutive patients in Ontario. Heart 1998;79:345-9.

2. Rao V, Christakis GT, Weisel RD, et al. Changing pattern of valve surgery. Circulation 1996;94:II113-20.

3. Magovern JA, Pennock JL, Campbell DB, et al. Aortic valve replacement and combined aortic valve replacement and coronary artery bypass grafting: predicting high risk groups. J Am Coll Cardiol 1987;9:38-43.

4. Lytle BW, Cosgrove DM, Gill CC, et al. Aortic valve replacement combined with myocardial revascularization: late results and determinants of risk for 471 in-hospital survivors. J Thorac Cardiovasc Surg 1988;95:402-14.

5. Lytle BW, Cosgrove DM, Taylor PC, et al. Primary isolated aortic valve replacement: early and late results. J Thorac Cardiovasc Surg 1989;97:675-94.

6. Jones EL, Weintraub WS, Craver JM, Guyton RA, Shen Y. Interaction of age and coronary disease after valve replacement: implications for valve selection. Ann Thorac Surg 1994;58:378-85.

7. Flameng WJ, Herijgers P, Szecsi J, Sergeant PT, Daenen WJ, Scheys I. Determinants of early and late results of combined valve operations and coronary artery bypass grafting. Ann Thorac Surg 1996;61:621-8.

8. David TE, Armstrong S, Sun Z. Clinical and hemodynamic assessment of the Hancock II bioprosthesis. Ann Thorac Surg 1992;54:661-8.

9. David TE, Uden DE. Aortic valve replacement in adult patients with small aortic annuli. Ann Thorac Surg 1983;36:577-83.

10. Edmunds LH, Clark RE, Cohn LH, Miller DC, Weisel RD. Guidelines for reporting morbidity and mortality after cardiac valvular operations. J Thorac Cardiovasc Surg 1996;112:708-11.

11. Aranki SF, Rizzo RJ, Couper GS, et al. Aortic valve replacement in the elderly: effect of gender and coronary artery disease on operative mortality. Circulation 1993;88:II17-23.

12. Jamieson WRE, Munro AI, Burr LH, Germann E, Miyagishima RT, Ling H. Influence of coronary artery bypass and age on clinical performance after aortic and mitral valve replacement with biological and mechanical prostheses. Circulation 1995; 92 (suppl):II-101-6.

13. David TE, Armstrong S, Sun Z. The Hancock II bioprosthesis at ten years. Ann Thorac Surg 1995;60:S229-34.

14. Czer LS, Gray RJ, Stewart ME, DeRobertis M, Chaux A, Matloff JM. Reduction in sudden late death by concomitant revascularization with aortic valve replacement. J Thorac Cardiovasc Surg 1988;95:390-401.

15. He G-W, Grunkemeier GL, Starr A. Aortic valve replacement in elderly patients: influence of concomitant coronary grafting on late survival. Ann Thorac Surg 1996;61:1746-51.

16. Lytle BW, Cosgrove DM, Loop FD, et al. Replacement of aortic valve combined with myocardial revascularization: determinants of early and late risk for 500 patients, 1967-1981. Circulation 1983;68:1149-62.

17. Jamieson WRE, Allen P, Miyagishima RT, et al. The CarpentierEdwards standard porcine bioprosthesis in 1190 patients for all valve positions. J Thorac Cardiovasc Surg 1990; 99:543-61.

18. Jamieson WRE, Burr LH, Tyers GFO, Munro AI. CarpentierEdwards standard and supra-annular porcine bioprostheses: 10 year comparison of structural valve deterioration. J Heart Valve Dis 1994;3:59-65.

19. Burr LH, Jamieson WRE, Munro AI, et al. Structural valve deterioration in elderly patient populations with the CarpentierEdwards standard and supra-annular porcine bioprostheses: a comparative study. J Heart Valve Dis 1992;1:87-91.

\section{Discussion}

Dr Robert W. Emery (Minneapolis, Minn). This paper reviews a 12-year retrospective experience with the Hancock II porcine bioprosthesis. After an elegant statistical review, an algorithm for the use of this prosthesis based on significant comorbid factors affecting long-term death is constructed, as you have just seen. In addition, many lessons are between the lines. Combinations of risk factors are particularly relevant in the prediction of long-term survival, as Dr Cohen has shown. Perioperative morbidity is clearly increased in the older age groups. The absence of aspirin was associated with an increased risk for thromboembolic events. And patients having prosthetic valve endocarditis did not survive in the absence of surgical therapy.

In reviewing the data, several other facts can be construed, and the conclusions, particularly related to the older age groups, questioned. The mean follow-up time of the series was 69 months and the median survival was 66 months in the older age group patients with CAD. However, the mean time 
of valve failure in the overall group was 87 months. In fact, the follow-up in the highest risk group, those patients over 65 years with coronary disease, was 56 months. After 6 years the number of patients at risk was small. Could these facts alter the algorithms suggested?

Coronary disease is a known negative determinant of longterm survival. The details of bypass grafting in this presentation were not ascertained. At the 1997 Society of Thoracic Surgeons (STS) meeting our group presented the results of a 15-year series of patients, having isolated AVR with a mechanical valve prosthesis as compared with those having AVR with the same prosthesis but having coronary bypass grafting. Similar to the current report, the actuarial survival curves split significantly at 6 months and remained different throughout the period reviewed, with the patients with coronary disease having poor survival. However, when the internal thoracic artery was used as a portion of the bypass procedure, the survival of patients having AVR with and without $\mathrm{CAD}$ was equivalent; that is, the use of the thoracic artery as part or the complete bypass operation, as opposed to saphenous veins alone with the concomitant AVR, improved the survival of those with coronary disease to the level of patients with valve replacement alone, extending over a 12-year follow-up period. This was not age dependent because the patient group over and under 70 years were both returned to the respective survival curves of similar patients having AVR who did not have CAD. Was the use of the internal thoracic artery as a conduit in construction of the bypass grafts evaluated in your data at all?

Additionally, the need for outflow tract enlargement was $19 \%$ overall. And in the older age group, the same. In the series of over 1500 mechanical valves mentioned, the performance of annular enlargement procedures was less than $1 \%$. Because the older patients are at increased risk for long-term morbidity and death, do you think the completion of a more complicated procedure in this higher risk group had any contribution to the overall long-term impact of increased morbidity and death?

The freedom from thromboembolic events was seemingly low, especially in the elderly patients. Freedom from thromboembolic events at 12 years in patients having internal thoracic artery versus those having saphenous vein graft, in the report we made at the STS meeting, was improved, 99\% versus $95 \%$, respectively. Did the addition of outflow tract reconstruction or the use of the internal thoracic artery (ITA) impact morbid long-term event rate?

Finally, the Toronto group has pioneered the use of stentless valves and reported excellent long-term freedom from PTF and excellent gradient relief. Does the approval and more common use of this valve modify the algorithm?

Dr Cohen. With regards to your comments on AVR with left internal thoracic artery (LITA), I was actually fortunate enough to have seen your data before. Although our data involve only tissue valves, I think that our results are somewhat generalizable to your results because none of the deaths in this group, or very few of these deaths, were valve related. I can also say that we have been using the LITA since 1984 regularly and that most of these patients, if not all of them, would have received an LITA.

Now, with respect to AVR revascularization, we found that patients with CAD had a poorer survival despite revascularization. And this isn't really all that surprising because CABG is really only a palliative procedure. I think that although your results are quite impressive, it may be difficult to generate any definitive conclusions because of the short follow-up period and the fact that there are relatively few numbers of patients in your cohort in the late time periods of follow-up. If you were to extend your follow-up period to 12 years or so, you may begin to see that the curves, the 2 curves, cross. Namely, for patients undergoing AVR with LITA, the curve starts to come down and the survival starts to come closer to patients in our group who had CAD with AVR.

The other thing I would like to say is that, obviously (and I know, Dr Emery, that your group puts in a lot of mechanical valves) if you can avoid reoperation by putting in a mechanical prosthesis, then by all means this should be your main objective. But I would not do so at any cost, because the risk of bleeding complications, especially in elderly patients, is quite high, in some series as high as $68 \%$. In that case, if a mechanical valve can be avoided, then it should. That is all I will say about mechanical valves.

With respect to your question about annular enlargement. Interestingly enough, we actually looked this up recently at the Toronto Hospital, and we compared patients who underwent annular enlargement with patients who were left with just a small prosthesis. What we found was quite interesting in that the functional status was improved; however, survival was not improved. Now, these are only preliminary results, such that I do not believe that the presence of patch enlargement, in our patients anyway, skewed our data in any way. But obviously, we will have to look into this further.

With respect to the high thromboembolic rate, you are correct in saying that there was a relatively low thromboembolic rate. We used to have a higher thromboembolic rate. What we used to do is discharge our patients with bioprostheses receiving warfarin (Coumadin) therapy only for 3 months, after which time they would not be receiving any anticoagulant therapy. Now, we keep them on warfarin therapy for 3 months and at discharge prescribe aspirin therapy. We seem to have seen a decrease in the event rate as far as thromboembolism is concerned in these patients.

And finally, with regard to your question about the Toronto SPV valve (St Jude Medical, Inc, St Paul, Minn), and I hope I do Dr David proud here, we have seen quite good results with our Toronto SPV valves. Dr David has recently reviewed our results. At 8 years postoperatively, our actuarial survival was $91 \%$ in SPVs when we compared them with a similar group of patients who received a Hancock II bioprosthesis. Freedom from cardiac-related deaths was $95 \%$ in Toronto SPV valves and $81 \%$ in Hancock II valves. Freedom from valve-related death, however, was similar in the two groups.

Now, we have recently reviewed the incidence of PTF in these same patients with Toronto SPV valves, and we found a 
trend toward PTF at about the same time that the Hancock II patients would start to experience PTF. So, although Toronto SPV valve may confer a survival benefit, I am not sure that it confers a benefit with respect to a PTF or increased durability.

Dr Manuel J. Irarrazaval (Santiago, Chile). Just one question. Dr David always is very strong on enlarging the anulus to avoid the gradient. I think it is reflected here in your $19 \%$ incidence of enlargement. Could you tell us something about the long-term survival results according to valve size and regression of left ventricular hypertrophy. Could you find some relationship there to justify this enlargement or is it bad news to leave a small anulus?

Dr Cohen. I think it would be premature to make any conclusions with respect to left ventricular mass regression. An earlier study of ours seemed to suggest that there is greater mass regression, and mass regression is achieved earlier in patients receiving the Toronto SPV valve. Now, unfortunately, those groups of patients were highly selected. We are currently undertaking a prospective, randomized trial where we are randomizing patients to either a Carpentier-Edwards or a Toronto SPV valve and comparing mass regression in these patients. Whether or not this is the reason for the improved survival in patients receiving the SPV valve, I cannot comment at this point, but that definitely could be a possibility.

Dr Bruce W. Lytle (Cleveland, Ohio). Dr Emery asked about the use of ITA grafts. If I understood your answer correctly, you said that you had used those grafts since 1984. I would then interpret that to mean that most of these patients had ITA grafts; is that correct?

Dr Cohen. Yes.

\section{ON THE MOVE?}

Send us your new address at least six weeks ahead

Don't miss a single issue of the journal! To ensure prompt service when you change your address, please photocopy and complete the form below.

Please send your change of address notification at least six weeks before your move to ensure continued service. We regret we cannot guarantee replacement of issues missed due to late notification.

\section{JOURNAL TITLE:}

Fill in the title of the journal here.

\section{OLD ADDRESS:}

Affix the address label from a recent issue of the journal here.
NEW ADDRESS:

Clearly print your new address here.

Name

Address

City/State/ZIP

\section{COPY AND MAIL THIS FORM TO:}

Periodical Subscription Services

Mosby, Inc.

11830 Westline Industrial Dr.

St. Louis, MO 63146-3318
OR FAX TO:

314-432-1158

N/ Mosby

\section{OR PHONE:}

1-800-453-4351

Outside the U.S., call

314-453-4351 